\title{
Do doctors experiencing burnout make more errors?
}

\author{
— Cite as: CMAJ 2018 October 9;190:E1216-7. doi: 10.1503/cmaj.109-5663
}

Posted on cmajnews.com on Sept. 20, 2018.

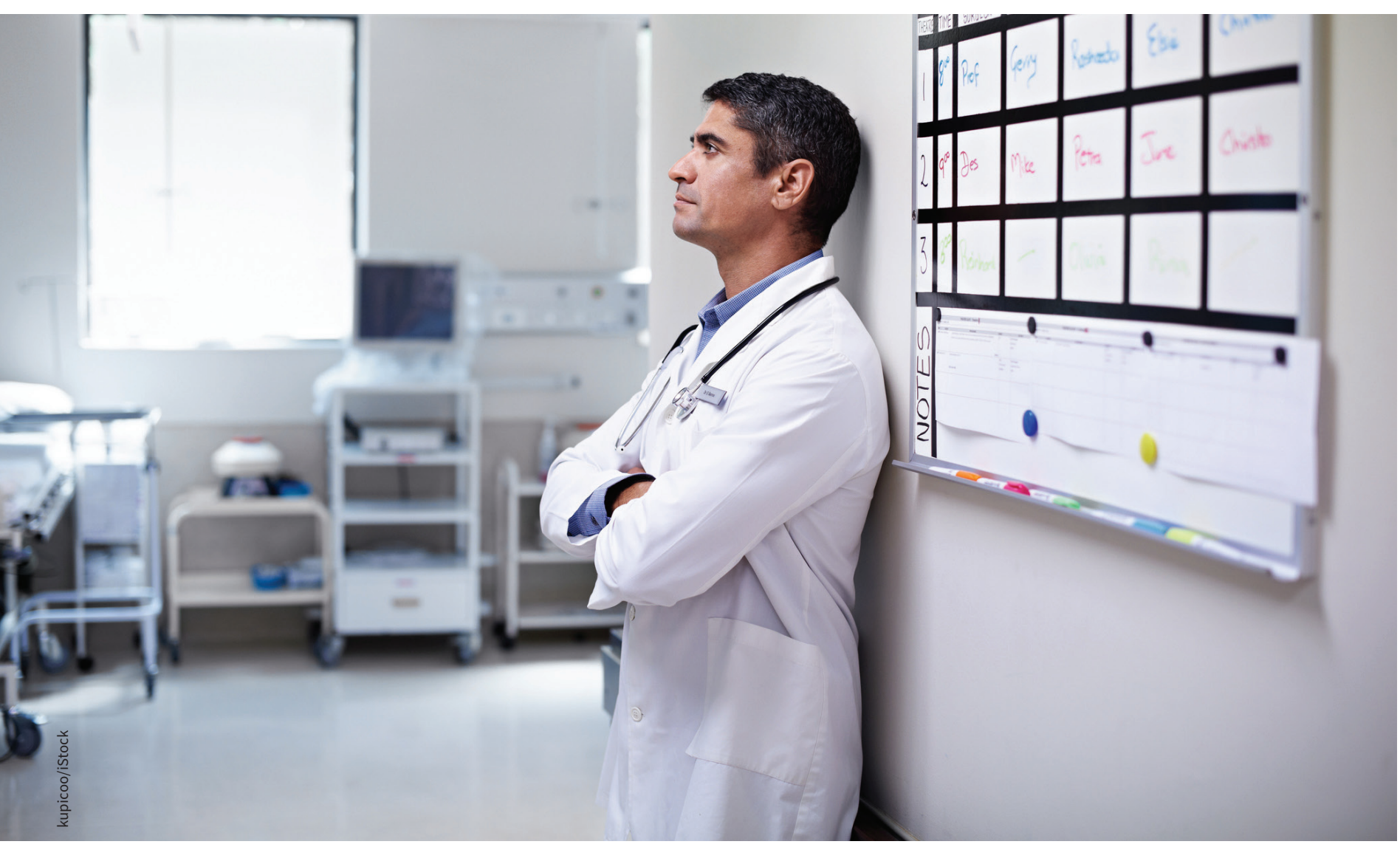

There has been growing attention to the effect of burnout on physician health, but what about the effect on patient outcomes?

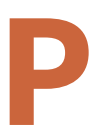

hysician burnout is not only potentially dangerous for doctors, but also for patients. Recent research linked burnout to medical errors across specialties, finding that doctors who report signs of burnout are twice as likely to have made a medical error in the previous three months.

Medical error is the third leading cause of death in the United States, after heart disease and cancer, according to a report in BMJ. An analysis of 2974 malpractice complaints in Canada found that most were about harms caused by doctor error.

In a recent study, published in Mayo Clinic Proceedings, Dr. Daniel Tawfik of Stanford University School of Medicine and colleagues surveyed a representative group of 6880 US physicians. The questionnaire billed itself as trying to learn more about factors underlying physician satisfaction.

Burnout was assessed using 22 standardized assessment questions, which were incorporated into the survey. Med- ical errors were probed with the question: "Are you concerned you have made any major medical errors in the last 3 months?" Six hundred and ninetyone doctors (10.5\%) answered "yes."

These physicians were then asked to describe the nature of the error and to say how things turned out. Most of the mistakes, they reported, were errors in judgment, wrong diagnoses or technical blunders. More than half had no serious consequences. But in 35 cases (5.3\%) a patient was left with "significant 
permanent morbidity." In 30 cases (4.5\%), the patient died.

Physicians whose surveys revealed signs of burnout were 2.2 times as likely to report a perceived medical error. But the researchers cautioned that the study does not show causality. In fact, they believe that just as burnout probably contributes to error, error probably contributes to burnout. Dr. Charlie Chan, chief medical officer at University Health Network in Toronto, agrees that burnout and the risk of medical error is a concern. Hospital systems are occasionally threatened with lawsuits by patients who claim that medical errors were caused by burnout, he says. As a result, some hospitals have changed the call schedules of training physicians, he says.

Tawfik's study shows that the problem goes beyond over-worked trainees and seems to apply across specialties. Previous studies have shown that surgeons, anesthesiologists and interns in intensive care units pose greater risk to patients when suffering from burnout. What to do about it is not obvious. Simply reducing physician hours does not always lead to improved well-being or fewer errors.

According to Tawfik and his colleagues, the observed association between burnout and errors is not limited to individuals at the extremes of the burnout spectrum; rather, it shows a continuum. "Institutions tend to focus on what proportion of physicians are 'burned out'," says Tawfik. "What this suggests is, even if doctors are not 'burned out', improving their well-being can help prevent errors."

Chan calls on all physicians to seek insight into their own physical and mental health. The myth that doctors can handle anything is "BS," he says, and "not sustainable." Doctors who recognize they're having difficulties will be helped. The burned-out physicians who are a real liability are the ones in denial, he says: "That's the situation where physicians harm more than just themselves."

Dr. Shelly Dev, an intensive care specialist at Sunnybrook Hospital in Toronto, says that more change is needed in the tone set by people in positions of power. Health care workers who feel they need time away worry deeply about how that will be perceived. Will it affect their ability to remain employed and be perceived as productive and competent?

"We've checked the box on calling out a problem," she says. "But translating that into real change has yet to happen." Dev was at first disheartened to think that doctor well-being might have to be linked to patient safety before it was given the public and administrative attention it deserved. But upon reflection, she said, if that's what it takes, "I'm okay with that."

Alison Motluk, Toronto 